\title{
EFEKTIVITAS PENGAWASAN DINAS PERTANIAN DAN PANGAN DALAM PEREDARAN DAGING BABI DI PASAR TRADISIONAL KABUPATEN BADUNG
}

\author{
I Made Aditya Wira Sanjaya, I Nyoman Putu Budiartha, Putu Ayu Sriasih Wesna \\ Fakultas Hukum Universitas Warmadewa, Denpasar-Bali, Indonesia \\ adityawira865@gmail.com, budiarthaputu59@gmail.com, ayuwesna@gmail.com
}

\begin{abstract}
Abstrak
Dalam dunia bisnis, pelaku dan konsumen (pemakaian barang atau jasa) sama-sama mempunyai kebutuhan dan kepentingan. Usaha bertujuan memperoleh laba dan transaksi dengan konsumen, sedangkan konsumen adalah memperoleh kepuasan dari segi harga dan mutu barang yang diberikan pelaku usaha. Penelitian ini bertujuan untuk menjelaskan perlindungan hukum terhadap konsumen yang mengkonsumsi daging babi di pasar tradisional Kabupaten Badung dan menjelaskan pengawasan Pemerintah melalui Dinas Pertanian dan Pangan Kabupaten Badung terhadap penjualan daging babi di pasar tradisional Kabupaten Badung. Penelitian ini menggunakan penelitian hukum empiris dan menggunakan pendekatan sosilogis hukum. Adapun sumber data yang digunakan yaitu data primer dan data sekunder. Teknik pengumpulan data yang digunakan dalam penelitian lain menggunakan teknik studi dokumen dan wawancara (interview). Dalam penelitian ini pengolahan dan analisis dilakukan secara kualitatif. Pelaksanaan ini di lakukan di dinas Pertanian Dan Pangan Kabupaten Badung. Aturan hukum terhadap konsumen sudah cukup memadai untuk melindungi hak-hak konsumen, selanjutnya efektivitasnya sudah dilakukan secara efektif oleh pemerintah daerah Kabupaten Badung
\end{abstract}

Kata kunci: Daging Babi, Efektivitas Pengawasan, Perlindungan Konsumen

\begin{abstract}
In the business world, actors and consumers (use of goods or services) both have needs and interests. The business aims to earn profits and transactions with consumers, while consumers are to obtain satisfaction in terms of the price and quality of goods provided by the business actor. This study aims to explain the legal protection of consumers who consume pork in the traditional markets of Badung Regency and explain the supervision of the Government through the Agriculture and Food Service of Badung Regency on the sale of pork in the traditional markets of Badung Regency. This research used empirical legal research and a sociological legal approach. The data sources used were primary data and secondary data. Data collection techniques used in other studies used document study techniques and interviews. In this study, the processing and analysis were carried out qualitatively. This implementation is carried out at the Badung Regency Agriculture and Food Service. The rule of law against consumers is sufficient to protect consumer rights, furthermore, its effectiveness has been carried out effectively by the local government of Badung Regency
\end{abstract}

Keywords: Pork, Supervision Effectiveness, Consumer Protection

\section{PENDAHULUAN}

Sebagaimana kewajiban Negara republik Indonesia adalah meningkatkan kesejahteraan rakyat seluruh Indonesia, secara materi maupun spiritual dengan tersedianya kebutuhan pokok sandang (pakaian), pangan (makanan), papan (perumahan) yang layak. Bisa dimakan atau dijual di pasaran dengan kualitas baik

Tujuan hukum adalah untuk mewujudkan keadilan, kemanfaatan, dan kepastian hukum (Ali, 2000). Dengan memperoleh hidup yang baik serta sehat bagi kemanusiaan itu dalam rangka menciptakan kesejahteraan serta kecerdasan, sangat penting juga adanya penyediaan makanan serta jasa dalam jumlah yang cukup banyak dan dengan harga yang terjangkau kepada masyarakat. Untuk memperoleh hidup yang sehat bagi masyarakat setempat perlu mewujudkan kesejahteraan dan kepintaran, itu perlu adanya tersedia bahan pokok makanan serta jasa yang banyak dan jumlah harga yang kecil bisa untuk diperjualbelikan kepada masyarakat. Namun memenuhi kebutuhan semua itu, masyarakat atau konsumen harus berhati-hati dalam memilih barang atau produk yang aman. Keluar masuknya barang dan jasa akan mempunyai manfaat bagi pembeli untuk bisa meraih barang atau produksi yang mereka inginkan dengan kualitas yang sangat baik. Pelaksanaan perlindungan 
konsumen merupakan salah satu pelaksanaan yang wajib dilakukan oleh pemerintah dalam setahun, untuk mengawasi pedagang atau konsumen akhir yang menjual produk babi di daerah pasar tradisional Badung. Pelaksanaan ini juga menyakinkan kepada masyarakat Badung khususnya dan masyarakat Bali umumnya bahwa daging yang mereka dibeli dan mereka konsumsi sudah memenuhi persyaratan atau sudah diawasi oleh pemerintah sehingga daging tersebut aman untuk dikonsumsi.

Pada saat hari raya besar di Bali yaitu hari raya galungan masyarakat sangat eksotis membeli daging babi karena salah satunya daging babi itu di perlukan untuk kepentingan upacara yadnya yang ada di Bali dan sekitarnya, permintaan pasar yang sangat melunjak sedangkan produsen akan secara gampang akan menaikan harga dan mengesampingkan kesehatan hewan atau daging babi tersebut. Fenomena yang terjadi di Kabupaten Badung mengejutkan peternak babi di daerah Badung, di dalam keadaan seperti ini pelaku usaha mencari keuntungan untuk membeli daging babi yang tidak layak atau tidak sehat untuk diperjualbelikan Kembali di pasar dengan harga yang normal, dalam hal ini tanggung jawab dari pemerintah salah satunya adalah untuk mengawasi dan membina kedudukan antara pelaku usaha, produsen dan pemerintah sama. bukan hanya di bidang politik tetapi juga di bidang sosial ekonomi, sehingga kesewenang- wenangan dari golongan karya harus di cegah oleh pemerintah (Dwipayana \& Artajaya, 2018). Upaya pencegaha ini perlu adanya upaya yang sungguhsungguh dalam memanfaatkan era globalisasi ini agar tetap terjamin peningkatkan kehidupan masyarakat dan memenuhi kebutuhan bahan pokok serta mencerdaskan kehidupan bangsa dan tidak mengenyampingkan hak-hak konsumen seperti kenyamanan, keamanan dan keselamatan.

Ada beberapa penelitian terdahulu terkait penelituan ini yaitu Maulidia, (2018); (Aprianty et al., 2019) mengungkapkan Penjual daging di pasar tradisional wajib mengikuti aturan dari pemerintah, sesuai dengan Pasal 19 ayat (1) Undang-Undang Perlindungan Konsumen adalah ganti ganti rugi berupa pengembalian uang. Putra \& Dev, (2020) mengungkapkan bahwa persediaan bahan baku, management supplay chain, dan modal berpengaruh positif terhadap pendapatan pedagang, selanjutnya Nida et al., (2020) mengungkapkan kerangnya efektifitas dalam pengawasan pasar tradisional sehingga terjadi pemalsuan daging babi dengan daging sapi. Dari penelitian terdahulu sudah banyak meneliti tentang sistem pasar tradisional, namun diketahui sampai saat ini masih banyak kejadian yang melanggar aturan pasar ,oleh sebab itu penelitian ini dilakukan bertujuan untuk menjelaskan perlindungan hukum terhadap konsumen yang mengkonsumsi daging babi di pasar tradisional kabupaten badung dan menjelaskan pengawasan pemerintah melalui dinas pertanian dan pangan kabupaten badung terhadap penjualan daging babi di pasar tradisional Badung

\section{METODE PENELITIAN}

Metode penelitian yang digunakan dalam penulisan ini adalah empiris yang dimana jenis penelitian lapangan yang mengkaji ketentuan hukum yang berlaku serta apa yang terjadi dalam kenyataan di masyarakat dengan pendekatan sosiologis hukum, pendekatan Undang-Undangan dan pendekatan konseptual (Bambang, 2002). Sumber data hukum yang digunakan adalah sumber hukum primer yaitu Undang-Undang Nomor 8 Tahun 1999 Tentang Perlindungan Konsumen, Selain itu juga terdapat hasil penelitian dengan wawancara kepada pihak terkait yaitu dinas pertanian dan pangan bidang kesehatan masyarakat veteriner data lapangan sebagai data primernya, sedangkan bahan hukum sekunder diperoleh dari teori-teori hukum lainya yang berkaitan dengan penelitian yang sedang dibahas.

\section{HASIL DAN PEMBAHASAN}

\section{Perlindungan Hukum Terhadap Konsumen yang Mengkonsumsi Daging Babi di Pasar Tradisional Kabupaten Badung}

Perlindungan konsumen tidak bisa lepas dari kegiatan bisnis yang sehat di Indonesia. Dalam bisnis yang sehat terdapat keseimbangan hukum antara konsumen dan produsen. Konsumen ada di posisi yang lemah karena tidak adanya perlindungan konsumen yang sangat serius diberikan kepada konsumen. Hukum perlindungan konsumen bisa dibagi dua jenis yaitu hukum preventif dan hukum represif (Bagiartha, 2013). Perlindungan hukum preventif adalah perlindunganyang diberikan kepada konsumen untuk mengawasi konsumen sebelum terjadinya pelanggaran yang dilakukan oleh pemerintah. Perlindungan hukum ini lebih mengacu kepada konsumen atau masyarakat yang diterapkan pemerintah setempat. Pemerintah melindungi konsumen dengan sebaik-baiknya dan menegakan hukum secara adil. Perlindungan hukum preventif adalah hukum yang diberikan kepada 
konsumen untuk menjaga dan mengawasi konsumen yang diberikan oleh pemerintah atau pengawas setempat . dengan adanya perlindungan hukum yang preventif pemerintah terdorong untuk bersikap hati-hati untuk mengambil keputusan yang didasarkan pada diskresi (Hadjon, 1993).

Hukum represif bertujuan untuk bisa menyelesaikan sengketa konsumen, penyelesaian sengketa dalam hukum represif ini dilakukan oleh badan peradilan atau yang berwenang secara absolut maupun relative, penyelesaian sengketa ini dilakukan dengan litigasi dan non litigasi. Secara litigasi diselesaikan melalui pengadilan. penyelesaian sengketa dengan non litigasi dengan di bentuk Badan pengawasan pengawasan yang berada di Indonesia. Dalam prakteknya juga kepala bidang Kesehatan masyarakat veteriner dinas pertanian dan pangan Kabupaten Badung menjelaskan selain melakukan sidak sempel mengenai daging yang akan dikonsumsi oleh konsumen atau masyarakat itu aman,sehat, utuh, dan halal, tetapi juga ada kegiatan penyuluhan terhadap produsen di pasar tradisional Kabupaten Badung tentang Kesehatan masyarakat veteriner dan hak-hak konsumen serta jenis-jenis konsumen.

Bahwa dinas pertanian dan pangan Kabupaten Badung terdapat satu (1) bidang kitu mempunyai tugas atau program yaitu pengambilan sampel ke seluruh pasar tradisional kabupaten badung, bidang tersebut yaitu bidang Kesehatan masyarakat veteriner yang kepala bidangnya yaitu Dra. I Gede Asrama M.M.A. tersebut mengatakan, tugas dari bidang kami memang benar ada pengambilan sampel dan pengujian laboratorium di UPT- Laboratorium Analitik kampus bukit Jimbaran Bali, kegiatan ini di lakukan di tahun 2019 yang dilakukan sebanyak empat (4) kali dalam setahun. Kepala bidang kesehatan masyarakat veteriner bapak Dra. I Gede Asrama M.M.A. menyatakan juga bahwa ditahun 2020 dikatakan pengambilan sampel tersebut ditiadakan sementara karena adanya sebab faktor-faktor, salah satu faktornya yaitu pandemic atau munculnya covid-19 di Indonesia tidak diperbolehkan berkerumunan dan tidak dibolehkan mengumpulkan masa dalam jumlah banyak. Program bidang Kesehatan masyarakat veteriner ini cuma sampai di pengambilan sampel daging babi dan pengecekan sampel di UPT- Laboratorium analitik kampus Bukit Jimbaran Bali, karena itu daging babi bisa di jual dan di konsumsi oleh masyarakat secara aman, sehat dan halal.

\section{Efektivitas Dinas Pertanian dan Pangan Terhadap Peredaran Daging Babi di Pasar Tradisional Kabupaten Badung}

Peranan Pemerintah dalam pengawasan perlindungan konsumen di dukung penuh melalui lembagalembaga yang dari pemerintah yaitu Badan perlindungan konsumen Nasional adalah badan yang dibentuk untuk membantu upaya pengembangan perlindungan konsumen dan Badan Perlindungan Konsumen Nasional memberikan saran dan rekomendasi kepada pemerintah dalam rangka penyusunan kebijakan di bidang perlindungan konsumen, Badan Perlindungan Konsumen Nasional dibentuk oleh Peraturan Pemerintah (PP) Nomor 4 Tahun 2019 tentang Badan Perlindungan Konsumen Nasional.

Badan Perlindungan Konsumen Nasional (BPKN) berkedudukan di Jakarta dan bertanggung jawab langsung kepada Presiden. Jika diperlukan Badan Perlindungan Konsumen Nasional (BPKN) dapat membentuk perwakilan di Ibu kota Provinsi. Lembaganya perkembangan perlindungan konsumen di negara berkembang yang perkembangan industrinya baru pada tahap permulaan karena sikap pemerintah pada umumnya masih melindungi kepentingan industri yang merupakan faktor yang esensial dalam pembangunan Negara (Ahmad Miru, 2013). Dalam hal ini juga ada terdapat salah satu tugas-tugas di bidang Kesehatan masyarakat veteriner Dinas Pertanian Dan pangan Kabupaten Badung, Berdasarkan hasil wawancara dengan kepala seksi Kesehatan masyarakat veteriner, Dinas Pertanian dan Pangan Kabupaten Badung tanggal 1 Desember 2020 disebutkan bahwa Tugas kita disini meyakinkan bahwa daging atau produk hewan yang dikonsumsi oleh masyarakat itu layak dikonsumsi, antara lain nya aman, sehat dan halal (daging sapi) kita mengambil sampel di pasar tradisional Kabupaten Badung itu kita ambil sampel dan kita uji laboratorium bekerja sama dengan laboratorium analitik di udayana dan keswan, balai besar veteriner, rutin pengambilan sampel di pasar tradisional. Selain Badan Perlindungan Konsumen Nasional ada Lembaga-lembaga yang mendukung penuh Badan Perlindungan Konsumen Nasional ini yang salah satunya dari pemerintah yaitu Badan Perlindungan Sengketa Konsumen, Lembaga ini diamanatkan oleh Undang-Undang setiap Kota/Kabupaten di suatu daerah harus mempunyai Lembaga ini tetapi di Bali ada satu Badan Perlindungan Sengketa Konsumen yang berada di Kota Denpasar dan ada juga Lembaga swasta yaitu 
Lembaga Perlindungan Konsumen Swadaya Masyarakat adalah lembaga non pemerintah yang terdaftar dan diakui oleh pemerintah yang mempunyai kegiatan mengenai perlindungan konsumen. Yayasan Lembaga Konsumen Indonesia merupakan organisasi masyarakat yang bersifat nirlaba dan independen yang didirikan pada tanggal 11 Mei 1973. Keberadaan Yayasan Lembaga Konsumen Indonesia (YLKI) diarahkan pada usaha meningkatkan kepada kritis konsumen atas hak dan kewajibannya dalam upaya melindungi dirinya sendiri, keluarga serta lingkungan.

Berdasarkan hasil dari wawancara dengan Dra. I Gede Asrama M.M.A. yang menjabat sebagai kepala bidang Kesehatan masyarakat veteriner menyebutkan bahwa kegiatan pengambilan sampel itu tahun 2019 ini dilakukan sebanyak empat(4) kali selama setahun yang ada pada bulan april, juni, agustus dan oktober yang ditahun ini tidak dilakukan pengambilan sampel dikarenakan ada beberapa faktor-faktor yang salah satunya yaitu pandemik yang menimpa di daerah Kabupaten Badung. Pandemi ini membuat pengambilan sampel di pasar Badung sangat tertunda, pengambilan sampel ini sangat diperlukan oleh masyarakat Kabupaten Badung agar Kesehatan masyarakat terjamin. Pengambilan sampel ke pasar-pasar kabupaten badung ini akan berjalan nantinya jika pandemik sudah berakhir, karena pengambilan sampel ini harus menurunkan anggota yang banyak dan peraturan belum membolehkan adanya kerumunan melebihi dari 50 orang ucap dari kepala bidang. Kesehatan masyarakat veteriner dinas pertanian dan pangan kabupaten badung itu.

Laporan pengujian nomor 115/UN.14.24/UPTLA/2018 jenis sampel bahan pangan hewani (daging) terdiri dari 6 jenis sampel yaitu daging ayam, hati ayam, daging babi, hati babi, daging sapi serta hati sapi dari data tersebut maka sampel yang sudah diuraikan diatas maka semua sempel menunjukan negative salmonella, dari itu bisa disimpulkan bahwa daging ayam, hati ayam, daging babi, hati babi, daging sapi dan hati yang sudah beredar di pasar tradisional kabupaten badung yang masyarakat terima tersebut layak dikonsumsi serta aman dan baik. Bukan hanya jenis sampel salmonella ada juga jenis sampel dari residu Antibiotika bahwa dari laporan hasil pengujian Nomor: 115/UN.14.24/UPTLA/2018 jenis sampel bahan pangan hewani (daging) dan jumlah sampel 176 (88A dan 88B), jenis daging dan jumlah daging itu adalah 29 daging ayam, 21 hati ayam, 18 daging babi, 12 hati babi, 5 daging sapi dan 3 hati sapi. Sudah dinyatakan negatif residu antibiotika.

Berdasarkan data di lapangan bahwa pengawasan Dinas Pertanian dan Pangan Kabupaten Badung di bidang Kesehatan masyarakat veteriner dalam peredaran daging babi tersebut sudah dinyatakan efektif, terbukti dalam semua jenis-jenis pengambilan sampel negative residu antibiotika, berartifungsi pengawasan itu sudah berjalan dengan baik

\section{SIMPULAN DAN SARAN}

\section{Simpulan}

Berdasarkan hasil analisis data, dapat disimpulkan bahwa Perlindungan hukum konsumen dibedakan menjadi dua jenis yaitu perlindungan hukum preventif dan hukum represif, Perlindungan hukum preventif adalah perlindungan hukum yang diberikan oleh pemerintah dengan tujuan untuk mencegah sebelum terjadinya pelanggaran. Hal ini terdapat memberikan rambu- rambu atau batasan-batasan dalam melakukan suatu kewajiban dan perlindungan hukum represif merupakan hukum yang menyelesaikan sengketa, selanjutnya upaya yang dapat dilakukan oleh Dinas Pertanian dan Pangan Kabupaten Badung dalam hal efektivitas peredaran daging babi di pasar tradisional Kabupaten Badung adalah dengan cara melakukan uji laboratorium pada daging sehingga konsumen dan pelaku usaha lebih mengetahui jenis-jenis daging babi yang layak untuk dikonsumsi. Berdasarkan data lapangan masih banyak konsumen dan pelaku usaha yang belum mendapatkan informasi dan edukasi mengenai daging babi yang layak dikonsumsi. Karena konsumen kurang tanggap meskipun pengawasan pemerintah juga telah memberikan edukasi dan informasi melalui media televisi dan radio.

\section{Saran}

Adapun saran yang diberikan melalui penelitian ini adalah diharapkan kepada masyarakat agar lebih mengetahui tentang pentingnya perlindungan hukum terhadap pedagang untuk mengkonsumsi daging babi di pasar tradisional Kabupaten Badung dan masyarakat harus lebih memahami terkait hak-hak yang dimilikinya sebagai konsumen, sehingga konsumen harus mempelajari dengan baik mengenai hak-hak mereka peroleh berdasarkan peraturan perundang-undangan yang berlakusehingg terhindar dari kerugian-kerugian yang tidak diinginkan, selanjutnya bagi pelaku usaha wajib mempelajari dengan baik terkait dengan pangan daging babi yang layak atau tidak untuk dikonsumsi 
serta harus lebih terbuka kepada konsumen mengenai kualitas daging babi yang dijualnya agar terciptanya hubungan yang baik yang berkelanjutan antara pelaku usaha dengan konsumen.

\section{DAFTAR PUSTAKA}

Ali, A. (2000). Menguak Tabir Hukum Kencana. Jakarta: Kencana.

Aprianty, D., Deliana, E., \& Dasrol, D. (2019). Tanggung Jawab Pelaku Usaha yang Menjual Daging Tidak Layak Konsumsi di Pasar Tradisional Dupa Kota Pekanbaru. JOM Fakultas Hukum, 6(1), 1689-1699.

Bagiartha, I. P. P. (2013). Kepastian Perlindungan Hukum bagi Konsumen atas Pemberlakuan Kontrak Baku. Kajian Hukum Dan Keadilan, 1(1), 60-76.

Bambang, W. (2002). Penelitian Hukum dalam Praktek. Jakarta: Sinar Grafika.

Dwipayana, I. K. A., \& Artajaya, G. S. (2018). Hegemoni Ideologi Feodalistis dalam Karya Sastra Berlatar Sosiokultural Bali. Jurnal Kajian Bali, 8(22), 84-104.

Hadjon, P. M. (1993). Penghantar Hukum Administrasi. University Press.

Maulidia, R. (2018). Bisnis Ritel Pangan di Pasar Tradisional. Jurnal Kodifikasia, 12(2), 260-274.

Nida, L., Pisestyani, H., \& Basri, C. (2020). Studi Kasus: Pemalsuan Daging Sapi dengan Daging Babi Hutan di Kota Bogor. Jurnal Kajian Veteriner, 8(2), 121-130.

Putra, P. C. P., \& Dev, S. (2020). Pengaruh Bahan Baku, Management Supplay Chain, dan Modal Terhadap Pendapatan Pedagang Sate di Kecamatan Abiansemal Kabupaten Badung Tahun 2020. Jurnal Ilmiah Mahasiswa Akuntansi Undiksha, 11(3), 597-606. 